\title{
Human Machine Interface for Automation System of Handling Station
}

\section{Human Machine Interface untuk Sistem Otomasi Handling Station}

\author{
Al Amin ${ }^{1 *}$, Risfendra ${ }^{1}$
}

\begin{abstract}
Industries have implemented automation technology to increase their productivity. One machine that applies automation technology is the handling station. This machine is useful for moving parts or components in the industry. For the performance of this machine to be monitored directly, we need a system that can control and monitor the work process of this tool. This article is an explanation of the results of the study aimed at designing the HMI handling station automation system using a PLC as its controller, HMI as a media for operation and monitoring of machines, magnetic sensors, inductive sensors and pressure sensors to detect machine conditions. Research conducted using quantitative methods. After testing, the system can be monitored and controlled through HMI, besides that data recording carried out with a data logger can also record the system work process directly when the system is run.
\end{abstract}

\section{Keywords}

Handling Station, HMI, PLC, Pneumatic,

\begin{abstract}
Abstrak
Industri-industri telah menerapkan teknologi otomasi untuk meningkatkan produktifitasnya. Salah satu mesin yang menerapkan teknologi otomasi adalah handling station. Mesin ini berguna untuk memindahkan barang atau komponen di industri. Agar kinerja dari mesin ini dapat dimonitor secara langsung diperlukan suatu sistem yang dapat mengendalikan dan memantau proses kerja alat ini. Artikel ini merupakan pemaparan hasil penelitian yang bertujuan untuk merancang HMI sistem otomasi handling station menggunakan PLC sebagai kontrolernya, HMI sebagai media pengoperasian dan pemantauan mesin, sensor magnetik, sensor induktif dan sensor pressure untuk mendeteksi kondisi mesin. Penelitian yang dilakukan menggunakan metode kuantitatif. Setelah pengujian dilakukan, sistem dapat dipantau dan dikendalikan melalui HMI, selain itu perekaman data yang dilakukan dengan data logger juga dapat merekam proses kerja sistem secara langsung saat sistem dijalankan.
\end{abstract}

\section{Kata Kunci}

Handling Station, HMI, PLC, Pneumatik

\author{
${ }^{1}$ Jurusan Teknik Elektro, Universitas Negeri Padang \\ Fakultas Teknik, Kampus UNP Air Tawar, Jl.Prof.Dr.Hamka,Padang \\ *alektro32@gmail.com \\ Submitted : July 9, 2019. Accepted : August 4, 2019. Published : September 1, 2019
}




\section{PENDAHULUAN}

Mesin produksi di industri telah menerapkan teknologi untuk mengoptimalkan kinerjanya dan mengurangi kesalahan yang disebabkan oleh manusia. Dengan menerapkan teknologi otomasi proses produksi dapat dilakukan secara cepat, dan bisa beroperasi 24 jam. Sehingga kapasitas produksi tercapai.

Handling station merupakan mesin produksi yang umum digunakan di industri. Handling station dibutuhkan untuk memindahkan material atau peralatan tertentu, bongkar dan memuat barang. Untuk memenuhi permintaan produksi handling station ini harus bisa bekerja tanpa henti, otomatis, serta termonitor. Sehingga jika terjadi kesalahan, operator dapat mengetahui kesalahan dari sitem tersebut.

Pada artikel ini handling station digunakan untuk proses pemindahan tutup wadah yang berbentuk lingkaran. Untuk itu diperlukan suatu sistem otomasi yang dapat mengontrol dan melakukan pemantauan proses handling secara langsung, cepat, dan efisien.

Suatu sistem otomasi biasanya gabungan dari sistem elektrik, mekanik, hidrolik dan pneumatik. Umumnya PLC digunakan sebagai otak dari sistem otomasi tersebut Untuk mempermudah pengoperasian dan pemantauan suatu sistem, biasanya juga dilengkapi dengan HMI yang dihubungkan dengan PLC. PLC atau Programable Logic Controler merupakan komputer khusus yang dirancang untuk mengontrol suatu proses atau mesin[1]. Komponen penyusun PLC terdiri dari; (1) CPU (2) Memori (3) Catu daya (4) Input/Output modul. Ada beberapa metoda atau model pemograman pada PLC yaitu: (1) Ladder Diagram (2) Instruction List (3)Function Blok Diagram (4) Sequence Flow Chart (5) Sturctured Text. Metoda yang umum digunakan adalah ladder diagram. Karena pemograman relatif lebih mudah dibandingkan metoda lain.

PLC yang digunakan adalah PLC Siemens S7-300. PLC ini bersifat modular, artinya I/O dari PLC ini bisa ditambah. Pada PLC yang digunakan memiliki 24 slot input digital dan 16 slot output digital. Modul analog berjumlah 12, 8 slot untuk input analog dan 4 slot untuk output analog. HMI atau Human Machine Interface berguna untuk menjembatani antara manuasia dan mesin sehingga operator dapat memantau dan mengendalikan mesin dengan mudah melalui komputer. Selain itu HMI juga dapat membantu dalam peningkatan kinerja mesin dan perekaman data[2]. HMI memiliki kemampuan untuk mengumpulkan dan mengolah informasi yang didapat dari mesin yang dikontrol menjadi informasi yang mudah dimengerti oleh manusia[3]. Pada HMI juga terdapat visualisasi pengendali mesin berupa tombol, slider,dan sebagainya yang dapat difungsikan untuk mengendalikan mesin sebagaimana mestinya[4].

Pneumatik merupakan cabang teori aliran atau mekanika fluida dan tidak hanya meliputi penelitian aliran-aliran udara melalui suatu sistem saluran beserta aksi penggunaan udara bertekanan[5]. Sistem pneumatik merupakan sistem yang menggunakan tenaga yang disimpan dalam bentuk udara yang dimampatkan serta dimanfaatkan untuk menghasilkan suatu kerja[6]. Kerja yang dimaksud adalah gerakan aktuator. Aktuator dapat berupa aktuator yang bergerak linier, dan rotasi. Berdasarkan cara kenjanya aktuator linier terdiri dari single acting dan double acting. Kendali pneumatik menggunakan sinyal listrik disebut dengan elektropneumatik[7]. Keluar masuknya udara bertekan ke aktuator dikendalikan malalui sebuah katup, katup ini diaktifkan dengan sinyal listrik biasanya disebut katup selenoid.

Handling station pada penlitian ini merupakan bagian pertama dari 3 bagian sistem otomasi pada trainer set elabo, bagian kedua yaitu mounting yang berguna untuk memasang atau membuka tutup, dan bagian ketiga yaitu storage berguna untuk penyimpanan pallet[8]. Dalam memudahkan untuk memahami sebuah alat biasanya dibantu dengan diagram alir proses alat bekerja. Diagram alir menjelaskan siklus alat bekerja. 


\section{METODE PENELITIAN}

Metoda penelitian yang digunakan yaitu kuantitatif, dimulai dari penggambaran alat secara ringkas melalui blok diagram, pengalokasian alamat I/O, pengawataan, dan perancangan ladder diagram serta tampilan HMI yang akan digunakan.

Blok diagram dapat memberikan gambaran ringkas mengenai alat yang akan dirancang. Ini adalah langkah awal dalam perancangan dan pembuatan alat. Blok diagram sistem otomasi handling station ini dijabarkan pada Gambar 1.

Berikut fungsi dari masing-masing bagian blok diagram.

1. PC berfungsi memprogram HMI dan PLC.

2. PLC merupakan otak dari sistem handling station ini.

3. HMI berfungsi sebagai media antarmuka untuk mengendalikan dan pemantauan sistem.

4. Sensor magnetik, sistem ini memiliki 4 buah sensor magnetik. Sensor magnetik ini berfungsi untuk mendeteksi posisi pallet, lifting, stopper magazine 1 dan 2 .

5. Sensor Inductive Proximity, sistem ini memiliki 4buah sensor inductive proximity. Sensor ini digunakan sebagai pendeteksi posisi lengan di depan, lengan di atas magazine, suction device, dan memiliki pallet telah memakai tutup.

6. Sensor Pressure, digunakan untuk mendeteksi tutup telah terhisap atau tidak.

7. Driver motor berfungsi merubah arah putaran motor dan merubah kecepatan motor.

8. Motor DC berfungsi menggerakan konveyor kearah kanan atau kiri.

9. Solenoid Valve berfungsi untuk mengatur pergerakan silinder pneumatik.

10. Silinder pneumatik berfungsi sebagai aktuator untuk sistem otomasi ini.

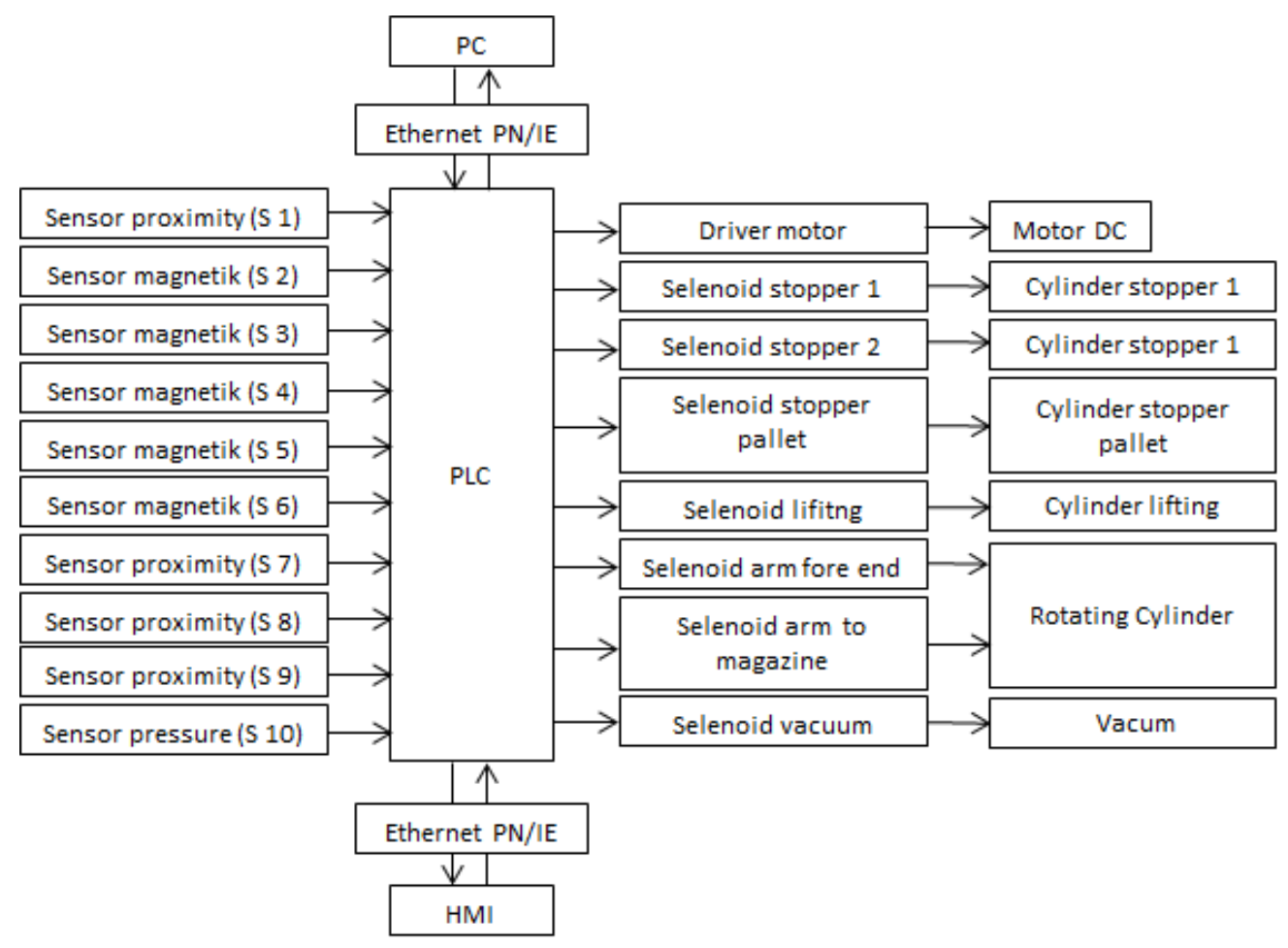

Gambar 1. Blok diagram sistem handling station

Agar dapat diprogram semua output dan input harus memiliki alamat, selain itu juga dapat mempermudah dalam pengalokasian I/O PLC. Pada sistem otomasi handling station ini digunakan satu buah PLC, untuk pengalamatan I/O PLC dicantumkan pada Tabel 1. 
Tabel 1. Alokasi alamat I/O handling station

\begin{tabular}{|c|c|c|c|}
\hline \multicolumn{2}{|l|}{ Alokasi Input } & \multicolumn{2}{|c|}{ Alokasi Output } \\
\hline Nama & Alamat & Nama & Alamat \\
\hline $\begin{array}{l}\text { Sensor proximity cover detect } \\
\text { (S1) }\end{array}$ & I 0.1 & Motor putar kiri (K1) & Q 0.1 \\
\hline Sensor magnetik pallet out (S2) & I 0.2 & Motor putar kanan (K2) & Q 0.2 \\
\hline Sensor magnetik stopper 1 (S3) & I 1.0 & Selenoid stopper 1 (K3) & Q 1.0 \\
\hline Sensor magnetik stopper 2 (S4) & I 1.1 & Selenoid stopper 2(K4) & Q 1.1 \\
\hline $\begin{array}{l}\text { Sensor magnetik stopper pallet } \\
\text { (S5) }\end{array}$ & I 1.2 & $\begin{array}{l}\text { Selenoid stopper pallet } \\
\text { (K5) }\end{array}$ & Q 1.2 \\
\hline Sensor magnetik lifting top (S6) & I 1.3 & Selenoid lifitng (K6) & Q 1.3 \\
\hline Sensor proximity arm fore end (S7) & I 1.4 & $\begin{array}{l}\text { Selenoid arm fore end } \\
\text { (K7) }\end{array}$ & Q 1.4 \\
\hline $\begin{array}{l}\text { Sensor proximity arm above } \\
\text { magazine (S8) }\end{array}$ & I 1.5 & $\begin{array}{l}\text { Selenoid arm above } \\
\text { magazine (K8) }\end{array}$ & Q 1.5 \\
\hline $\begin{array}{l}\text { Sensor proximity suction in touch } \\
\text { (S9) }\end{array}$ & I 1.6 & Selenoid vakum (K 9) & Q 1.6 \\
\hline Sensor pressure (S10) & I 1.7 & & \\
\hline
\end{tabular}

Dari tabel 1 terdapat sepuluh sensor yang dijadikan input PLC dan sembilan buah output yang terdiri dari selenoid valve dan driver motor. Rangkaian pengawatan input dan output sistem otomasi ini diperagakan pada Gambar 2. Seperti yang diperagakan pada Gambar 2 sistem ini menggunakan dua buah sinyal modul. Input yang digunakan adalah input digital, sensor hanya akan memberikan nilai 1 jika aktif dan 0 saat tidak aktif. Begitupun dengan output, yang digunakan juga output digital.

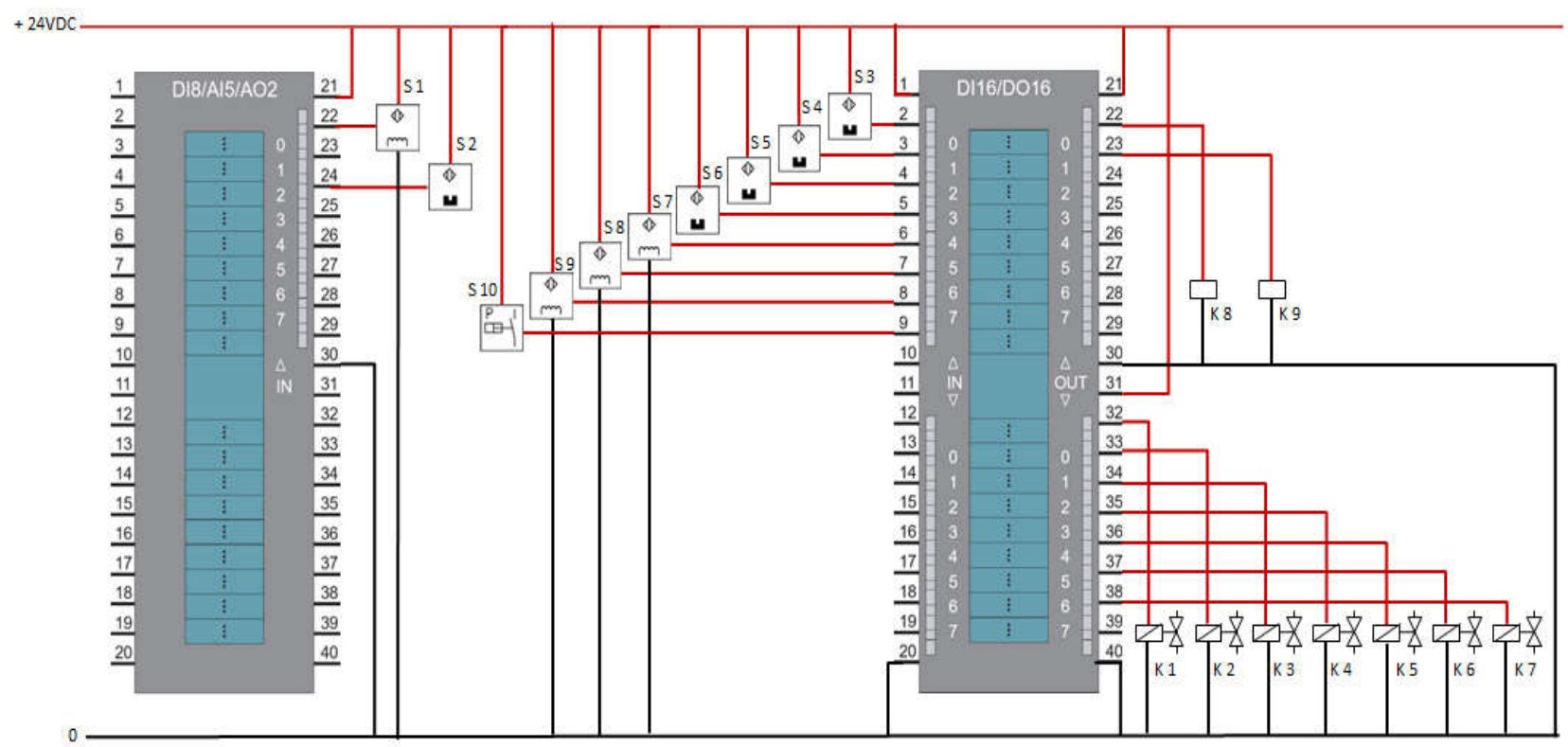

Gambar 2. Diagram Pengawatan I/O Handling Station 


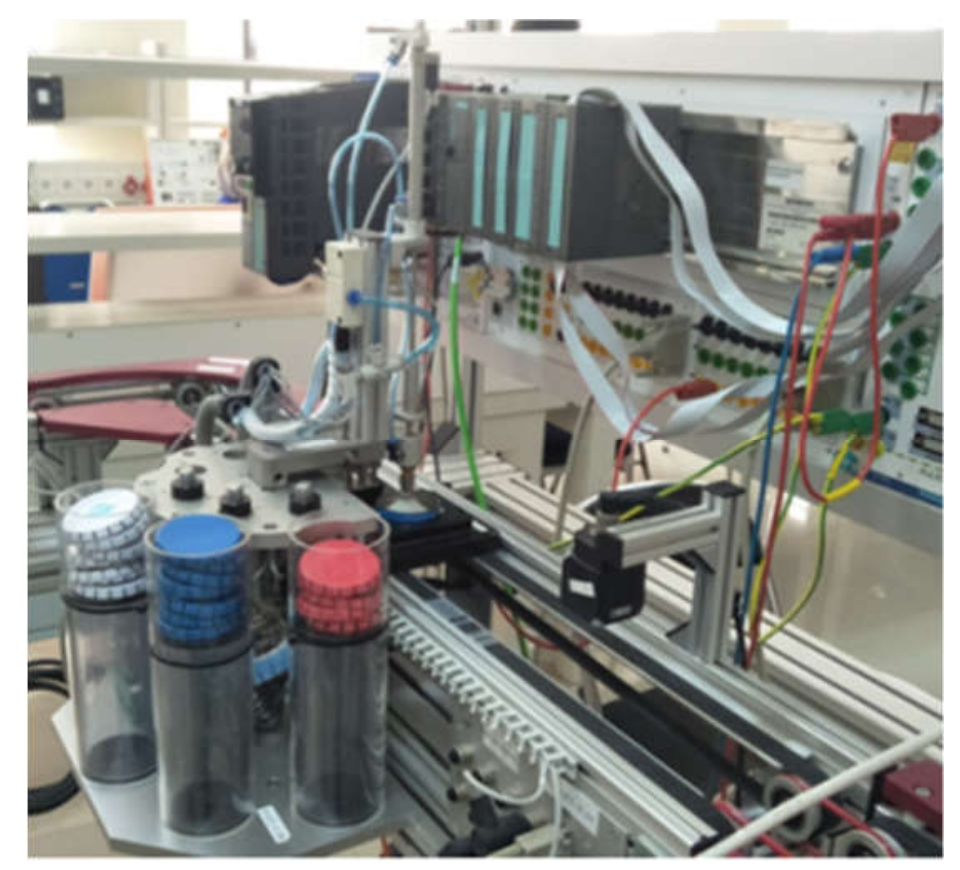

Gambar 3. Bentuk fisik handling station

Bentuk fisik handling station yang digunakan pada penelitian ini dapat dilihat pada gambar 3. Tujuan perancangan HMI pada sistem otomasi ini untuk pengendalian sistem handling, selain itu juga digunakan untuk pemantauan sistem. Proses pemantauan dilakukan secara langsung untuk menjaga kondisi barang dan memudahkan saat terjadi kesalahan sistem Rancangan HMI dari sistem otomasi ini dijabarkan pada Gambar 4.

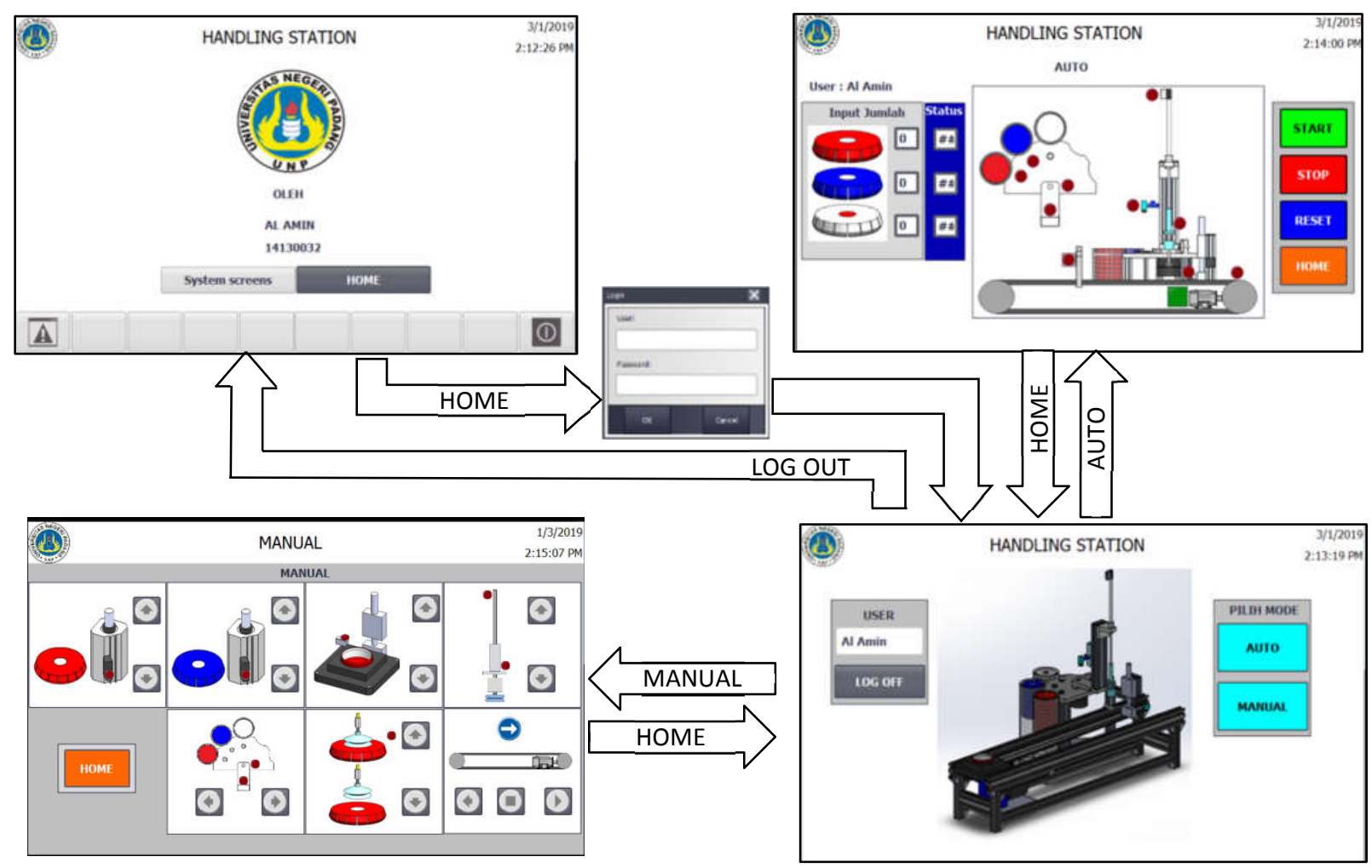

Gambar 4. Rancangan HMI Handling Station 
Seperti yang terlihat pada Gambar 4 terdapat 2 mode operasi yang digunakan pada sistem otomasi handling station ini yaitu mode otomatis dan manual. Dalam mode otomatis handling akan mengambil tutup berdasarkan jumlah yang diinputkan operator. Setiap aktuator akan bergerak otomatis berdasarkan sensor yang aktif. Sedangkan pada mode manual handling akan dikendalikan dengan menekan virtual button untuk masing-masing aktuator. Secara ringkas flowchart sistem otomasi handling station ini digambarkan pada Gambar 5.

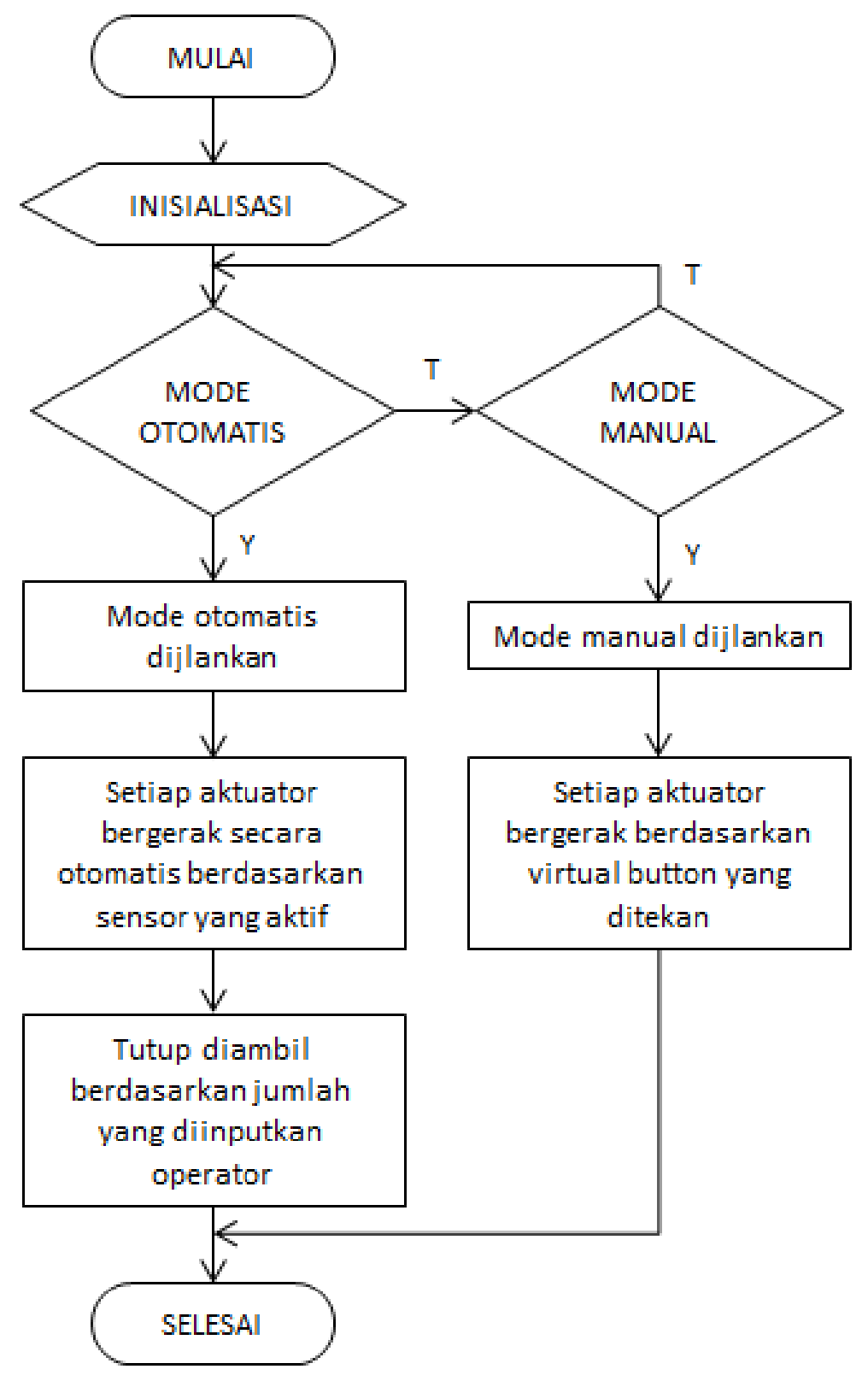

Gambar 5. Flowchart otomasi Handling Station

\section{HASIL DAN PEMBAHASAN}

Pengujian yang dilakukan pada tugas akhir ini meliputi pengujian proses kerja, analisa tampilan HMI, dan Data Logger monitoring sistem.

1. Urutan proses kerja alat

Urutan proses kerja alat mengacu pada diagram alir, proses pertama yaitu memilih mode operasi, jika mode operasi yang dipilih auto maka sistem akan otomatis bekerja 
memindahkan tutup sesuai jumlah yang diinputkan. Sedangkan pada mode manual sistem bekerja terpisah dengan menekan virtual button yang tampil pada layar HMI

2. Analisa tampilan HMI

Seperti yang terlihat pada gambar 3, sistem ini memiliki 4 tampilan (1)Tampilan awal (2)Tampilan HOME (3)Tampilan AUTO (4)Tampilan MANUAL. Pada Tampilan ini terdapat beberapa virtual button yang digunakan untuk mengoperasikan mesin. Selain itu juga terdapat beberapa indikator dan notifikasi yang digunakan untuk mengetahui kondisi mesin. Beberapa notifikasi dapat dilihat pada gambar 6.

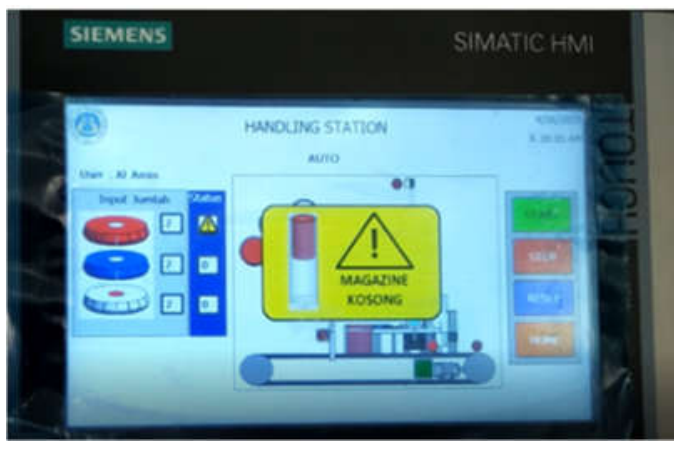

$\mathrm{a}$

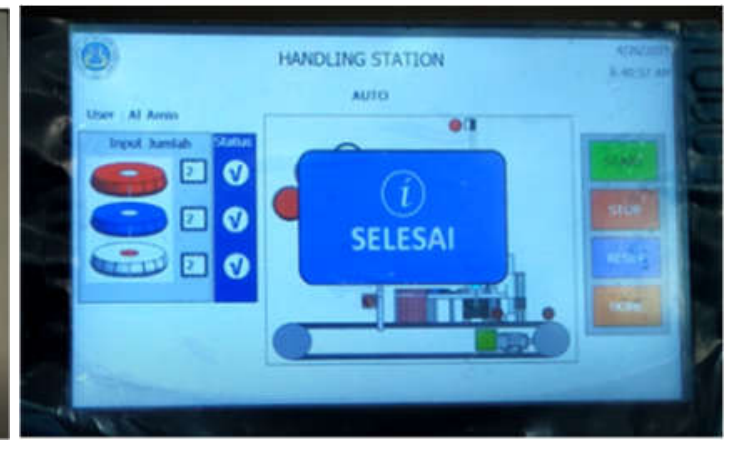

$\mathrm{b}$

Gambar 6. (a) Notifikasi magazine merah kosong dan (b)Notifikasi selesai

Tabel 2. Data logger handling station

\begin{tabular}{|l|l|l|l|}
\hline \multicolumn{1}{|c|}{ VarName } & \multicolumn{1}{|c|}{ TimeString } & VarValue & Time_ms \\
\hline Intput merah & $26.04 .201908: 56: 44$ & 2 & $4,36 \mathrm{E}+10$ \\
\hline Input biru & $26.04 .201908: 56: 45$ & 2 & $4,36 \mathrm{E}+10$ \\
\hline Input putih & $26.04 .201908: 56: 47$ & 2 & $4,36 \mathrm{E}+10$ \\
\hline Output merah & $26.04 .201908: 57: 12$ & 1 & $4,36 \mathrm{E}+10$ \\
\hline M notif merah kosong & $26.04 .201908: 57: 30$ & -1 & $4,36 \mathrm{E}+10$ \\
\hline M notif merah kosong & $26.04 .201908: 57: 37$ & 0 & $4,36 \mathrm{E}+10$ \\
\hline Output merah & $26.04 .201908: 57: 46$ & 2 & $4,36 \mathrm{E}+10$ \\
\hline Output biru & $26.04 .201908: 58: 11$ & 1 & $4,36 \mathrm{E}+10$ \\
\hline M notif biru kosong & $26.04 .201908: 58: 33$ & -1 & $4,36 \mathrm{E}+10$ \\
\hline M notif biru kosong & $26.04 .201908: 58: 42$ & 0 & $4,36 \mathrm{E}+10$ \\
\hline Output biru & $26.04 .201908: 58: 51$ & 2 & $4,36 \mathrm{E}+10$ \\
\hline Output putih & $26.04 .201908: 59: 16$ & 1 & $4,36 \mathrm{E}+10$ \\
\hline M notif putih kosong & $26.04 .201908: 59: 33$ & -1 & $4,36 \mathrm{E}+10$ \\
\hline M notif putih kosong & $26.04 .201908: 59: 41$ & 0 & $4,36 \mathrm{E}+10$ \\
\hline Output putih & $26.04 .201908: 59: 51$ & 2 & $4,36 \mathrm{E}+10$ \\
\hline Output merah & $26.04 .201909: 00: 11$ & 0 & $4,36 \mathrm{E}+10$ \\
\hline Output biru & $26.04 .201909: 00: 11$ & 0 & $4,36 \mathrm{E}+10$ \\
\hline Output putih & $26.04 .201909: 00: 11$ & 0 & $4,36 \mathrm{E}+10$ \\
\hline
\end{tabular}




\section{Data logger monitoring sistem}

Data logger merupakan proses penyimpanan data berkala pada suatu sistem. Data yang akan direkam pada sistem ini yaitu monitoring kondisi mesin, dan jumlah tutup pallet yang diambil. Tabel 2 merupakan data logger monitoring saat pengujian sistem.

Data logger ini hanya merekam data pada mode operasi auto. Data yang direkam yaitu jumlah yang diinputkan operator untuk masing-masing warna tutup (input merah, biru, putih), sisa pallet yang akan dipasang tutup (Output merah, biru, putih), dan waktu ketika tutup pada magazine habis.

\section{SIMPULAN DAN SARAN}

Dari penelitian yang dilakukan dapat disimpulkan perancangan dan penerapan HMI untuk sistem otomasi handling station berjalan sesuai dengan yang dirancang. HMI sebagai media pengoperasian sistem bekerja dengan baik, selain itu fungsi HMI sebagai monitoring juga berfungsi dengan baik.

\section{DAFTAR RUJUKAN}

[1] Setiawan, Iwan. (2006). "Programable Logic Controler (PLC) dan Teknik Perancangan Sistem Kontrol”. Yogyakarta : Andi.

[2] Faikar, Rousyan.dkk (2015). "Perancangan Sistem Antar Muka Berbasis HMI Pada Mesin YCP”. Semarang : Universitas Diponegoro.

[3] Priswanto, dkk. (2018). "Penerapan PLC HMI (Human Machine Interface) Untuk Monitoring Objek Pada Sistem Konveyor", LPPM Journal No. ISBN: 978-602-1643-617

[4] Haryanto,Heri, dkk. (2012). "Perancangan HMI untuk Kendali Kecepatan Motor DC". SETRUM - Volume 1, No. 2. ISSN : 2301-4652.

[5] Sudaryono. (2013) "Pneumatik dan Hidrolik". Jakarta : Kemendikbud.

[6] Widodo, Alex Tri Kantjono. (1985). "School Council Modular Courses in Technology PNUEMATIC" (Peter Patient, Roy Pickup, dan Norman Powell, Terjemahan). Inggris : Oliver \& Boyd. Buku asli diterbitkan tahun 1983.

[7] Roisul Fata, Muhammad. (2017). "Elektro Pneumatik dan PLC Siemens". Jakarta : Kemendikbud.

[8] Putra Dasril, Aldo. (2019). "Perancangan Human Machine Interface untuk sistem otomasi storage berbasis PLC”. JTEV-Volume V, No.1.ISSN:2302-3309

\section{Biodadata Penulis}

Al Amin, dilahirkan di IV Angkek, 6 Juli 1996. Menyelesaikan D IV Teknik Elektro Industri pada Jurusan Teknik Elektro Fakultas Teknik Universitas Negeri Padang.

Risfendra, S.Pd, M.T, Ph.D, lahir di Riau, 13 Februari 1979. Sarjana Teknik Elektronika di Universitas Negeri Padang, lulus tahun 2004, S2 Teknik Sistem Pengaturan, ITS tahun 2008. S3 Shouten Taiwan University of science and technology, Taiwan tahun 2017. Staf pengajar pada Jurusan Teknik Elektro FT UNP sejak tahun 2005 - sekarang. 